\title{
Sociocultural and epidemiological aspects of HIV/AIDS in Mozambique
}

\author{
Carolyn M Audet*1,2, Janeen Burlison1, Troy D Moon 1,3,4, Mohsin Sidat ${ }^{5}$, Alfredo E Vergara ${ }^{1,2}$ and Sten H Vermund1,3
}

\begin{abstract}
Background: A legacy of colonial rule coupled with a devastating 16-year civil war through 1992 left Mozambique economically impoverished just as the human immunodeficiency virus (HIV) epidemic swept over southern Africa in the late 1980s. The crumbling Mozambican health care system was wholly inadequate to support the need for new chronic disease services for people with the acquired immunodeficiency syndrome (AIDS).

Methods: To review the unique challenges faced by Mozambique as they have attempted to stem the HIV epidemic, we undertook a systematic literature review through multiple search engines (PubMed, Google Scholar ${ }^{\mathrm{TM}}$, SSRN, AnthropologyPlus, AnthroSource) using Mozambique as a required keyword. We searched for any articles that included the required keyword as well as the terms 'HIV' and/or 'AIDS', 'prevalence', 'behaviors', 'knowledge', 'attitudes', 'perceptions', 'prevention', 'gender', drugs, alcohol, and/or 'health care infrastructure'.

Results: UNAIDS 2008 prevalence estimates ranked Mozambique as the $8^{\text {th }}$ most HIV-afflicted nation globally. In 2007, measured HIV prevalence in 36 antenatal clinic sites ranged from 3\% to 35\%; the national estimate of was 16\%. Evidence suggests that the Mozambican HIV epidemic is characterized by a preponderance of heterosexual infections, among the world's most severe health worker shortages, relatively poor knowledge of HIV/AIDS in the general population, and lagging access to HIV preventive and therapeutic services compared to counterpart nations in southern Africa. Poor education systems, high levels of poverty and gender inequality further exacerbate HIV incidence.

Conclusions: Recommendations to reduce HIV incidence and AIDS mortality rates in Mozambique include: health system strengthening, rural outreach to increase testing and linkage to care, education about risk reduction and drug adherence, and partnerships with traditional healers and midwives to effect a lessening of stigma.
\end{abstract}

\section{Background}

Mozambique, a southeast African nation of $\approx 21$ million people, suffers one of the world's highest burdens of human immunodeficiency virus (HIV) and acquired immunodeficiency syndrome (AIDS) (Figure 1). In 2007, HIV prevalence in the 36 antenatal clinic (ANC) sentinel surveillance sites ranged from $3 \%$ to $35 \%$ with a national estimate of $16 \%$ (plausibility bounds from 14-17\%) in women ages 15-49 years [1]. Provincial HIV prevalence estimates ranged from $8 \%$ to $27 \%$ and were highest in the central and southern provinces [1]. The impact of the 10year armed struggle for independence from the Portuguese (1964-1974) and the 15-year externally financed

* Correspondence: carolyn.m.audet@vanderbilt.edu

1 Vanderbilt Institute for Global Health, Vanderbilt University School of Medicine, Nashville, TN, 37203 USA

Full list of author information is available at the end of the article insurgency (1977-1992) resulted in the devastation of industrial and governmental infrastructures, including health clinics and schools [2]. The end of war brought increased social and economic stability, but coincided with rising HIV/AIDS rates as Mozambique's national isolation ended.

The first case of HIV was reported in Mozambique in 1986 [3]. By 2001, one million people were estimated to be living with HIV, including 53,000 children under the age of 18 and 570,000 women [1]. In response, the MISAU developed a strategic framework focusing efforts on reduction of vertical transmission, prevention of HIV transmission in health facilities for nosocomial and occupational exposures, and improved access to life-saving treatment through expansion of its antiretroviral therapy (ART) program. Prior to 2004, ART was available only through pilot programs, with the majority of the popula- 


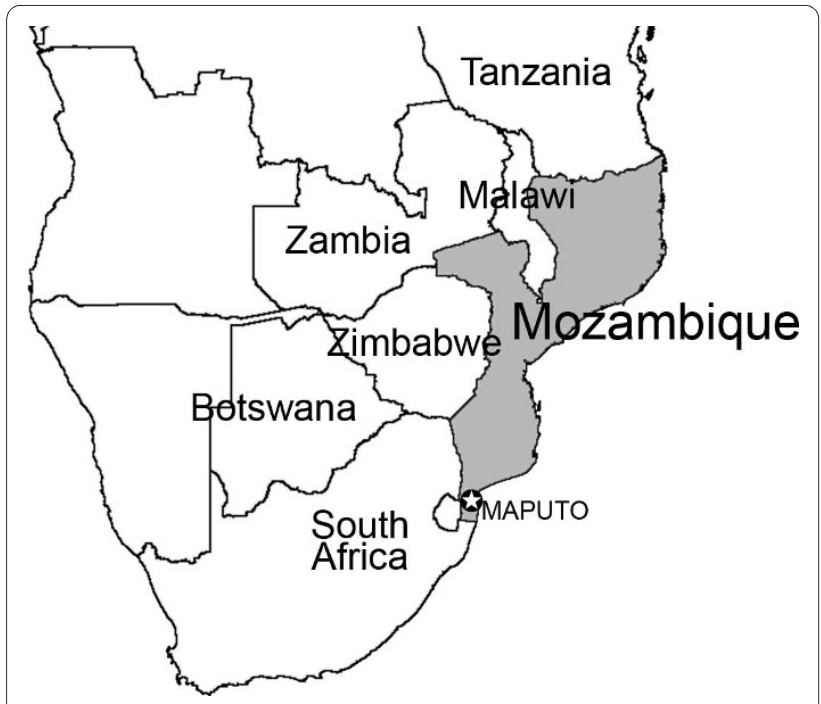

Figure 1 Map of Mozambique and surrounding countries.

tion given cotrimoxazole prophylaxis and medicine to manage opportunistic infections. ART became available nationwide in 2004 with the support of international funding agencies. Despite these efforts, $<25 \%$ of those with advanced HIV disease were receiving treatment in 2007. An estimated 1.5 million people were living with HIV in Mozambique in 2007, including 810,000 women and 100,000 children [1]. Annual deaths from AIDSrelated causes are estimated to have increased from approximately 45,000 people in 2000 to 97,000 in 2005 [4].

HIV prevalence varies markedly by region, sex, and age [1]. An estimated 58\% of adults living with HIV in 2007 were women, with fully three-quarters of the infected 1519 year olds being female (8.5\% prevalence in females and $2.9 \%$ in males) [1]. The higher prevalence in females may reflect a greater biological susceptibility to the disease, but is assuredly exacerbated by a multitude of cultural and social factors; women are offered HIV testing more regularly than men due to pregnancy and programs aimed to prevent vertical transmission of HIV $[1,4,5]$. This paper is designed to provide readers with an overview of the unique challenges to HIV prevention and treatment in Mozambique through a review of the sociological, anthropological, and epidemiological literature published relating to the HIV/AIDS epidemic.

\section{Methods}

We undertook a systematic literature review through multiple search engines (PubMed, Google Scholar ${ }^{\mathrm{m}}$, SSRN, AnthropologyPlus, AnthroSource) using Mozambique as a required keyword. We searched for any articles that included the required keyword as well as the terms 'HIV' and/or 'AIDS', 'prevalence', 'behaviors', 'knowledge', 'attitudes', 'perceptions', 'prevention', 'gender', drugs, alcohol, and/or 'health care infrastructure'. Further, we reviewed the citations of each article to identify other appropriate reports. Unpublished reports were requested from the Centers for Disease Control and Prevention (CDC) in Mozambique, the Joint United Nations Programme on HIV/AIDS (UNAIDS), the United Nations Children's Fund (UNICEF), the World Health Organization (WHO), and the Mozambique Ministry of Health (MISAU). We reviewed all articles published since 1990 that we felt were relevant $(n=100$ articles from total 130 with Mozambique and HIV or AIDS as key words) based on their epidemiological and/or behavioral data. We report here those key published data and observations that we felt relevant to impact of HIV in Mozambique. Our systematic literature review of the Mozambican HIV/AIDS epidemic highlights challenges to health care professionals, policy makers, and those providing social and education programming to the socio-cultural, anthropological and infrastructural challenges impeding HIV prevention and treatment.

\section{Results}

Unprotected heterosexual sex and vertical transmission are known risk factors for HIV infection in Mozambique [1]. However, neither male-to-male sexual contact nor use of unsafe needles has been studied adequately. Despite having infection rates that are among the highest in the world, individual risk perceptions among Mozambicans underestimate personal risk markedly $[6,7]$. In 2004, young women in Maputo demonstrated substantial difficulty in assessing their own risk even when they had correct knowledge about HIV transmission [8].

High risk activities, among both men and women, may be encouraged by local traditions and customs [9]. These include cultural rituals and norms such as 'widow cleansing', in which a brother-in-law or other male relative has sex with the wife of the deceased family member, early sexual initiation, intergenerational and transactional sex, and intravaginal practices such as vaginal instillation of desiccant herbs for 'dry sex' [5,10-13].

An underdeveloped primary care system and chronic health manpower shortages could potentially contribute to HIV transmission risk. For example, if sterile needles and syringes are not used for vaccination and health care HIV can be transmitted. Similarly, blood transfusions may transmit HIV in the absence of an excellent national blood banking system. Untreated co-infections such as tuberculosis, malaria, sexually transmitted infections (STIs), and geohelminthes can increase the likelihood of HIV transmission though dysregulation of host immunity and subsequent spikes in viral load (in HIV-infected) and immune activation (in both HIV-infected and uninfected); this can increase susceptibility of HIV-uninfected 
and disease progression and infectiousness of HIVinfected persons $[14,15]$.

\section{Heterosexual Risk Behavior}

A high prevalence of STIs, early age at first sexual experience, and the culturally accepted practice among some sub-groups to have multiple, concurrent partners are thought to substantially increase HIV transmission risk [16]. In 2007, the MISAU found median syphilis rates (by $\mathrm{RPR}$ ) to be $3 \%$ in clinics in the southern provinces (range $1-18 \%), 7 \%(1-16 \%)$ in the central provinces, and 12\% (1$26 \%)$ in the northern provinces; syphilis rates correlated poorly with regional HIV infection rates (Figure 2) [1]. HIV infection rates are higher in the southern and central parts of the country, with lower rates in the north. A 2007-2008 the MISAU study conducted in the city of XaiXai in Gaza Province and in Maputo documented a high prevalence of STIs in HIV-infected people on their first care visit, including syphilis (15.2\% were RPR and TPHApositive), trichomoniasis (10.2\% in men and $48.5 \%$ in women by PCR), bacterial vaginosis $(38.6 \%$ by Nugent's criteria), and vaginal candidiasis ( $10 \%$ on Gram stain) [17]. Notably, $86.8 \%$ of men and $94.8 \%$ of women were herpes simplex virus-2 (HSV-2) positive on serology [17].

Early sexual debut is common in Mozambique, with one survey reporting that $74 \%$ of Mozambican women had had their first sexual experiences before age 18 [18]. A 2002 national survey of reproductive health among 1524 year olds reported that $24 \%$ of females and $30 \%$ of males had intercourse before age 15 [5]. In the 2003 Demographic and Health Survey (DHS), the median age of first intercourse was 16.1 years for women and 17.8 for men [19]. Sexually active young women in neighboring

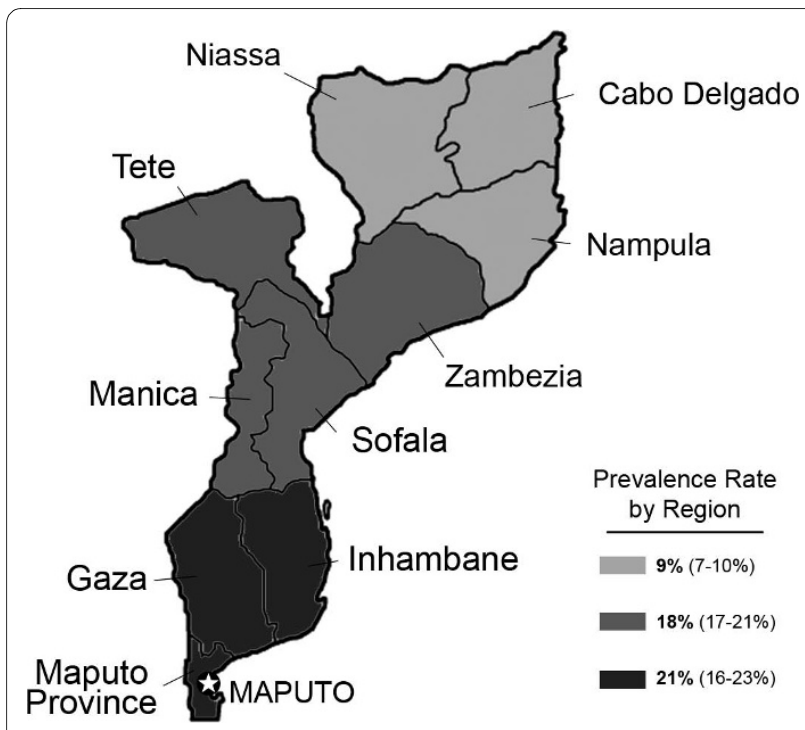

Figure $\mathbf{2}$ Map of Mozambique highlighting regional prevalence rates.
Zambia reported having sex with older partners who were potentially at higher risk for HIV infection, and it is likely that young Mozambican women are engaging in similar behavior [20]. Given that younger women may have a higher biological risk for contracting HIV and STIs due to presence of cervical ectopy (non-keratinized exocervical tissue), the benefits of delayed sexual initiation and condom use are especially important for adolescents [21].

\section{Socio-economic Diversity}

Distinctions in socioeconomic status, access to education, language, and gender relationships divide the northern, central and southern parts of the country. Despite its status as the official language of Mozambique, in 2003 Portuguese was spoken fluently by only $40 \%$ of the population [19]. Of the 42 languages spoken in Mozambique, 41 derive from the Bantu language family [22]. Reflecting the ethnic incoherence of colonial divisions that now constitute the borders of modern African nations, neighboring countries with strong linguistic links (examples are given) include South Africa (Zulu, Tsonga), Zambia (Nyanja, Nsenga), Malawi (Chichewa, Yao), Zimbabwe (Tsonga, Ndau), Swaziland (Swati, Tsonga), and Tanzania (Yao, Makonde). Mozambicans frequently migrate to South Africa and other nations of high HIV endemicity for both short- and long-term job opportunities [22,23]. This migration presents a challenge for the government, partner non-governmental organizations (NGOs), and faith-based organizations (FBOs). For example, Tonga men commonly migrate to South Africa to work in the mines for several years at a time, a well documented context for increased risk for themselves and their families [23]. Health care services and education for miners and their families have been limited, however [23]. As Mozambicans living in southern and central parts of the country are those mostly likely to migrate, this may contribute to high HIV infection rates.

Securing money to stay in school and/or buy goods or food has been identified as a reason for adolescent girls in sub-Saharan Africa to participate in sexual relationships [24-26]. Girls in the capital city of Maputo may engage in sexual relationships with older men in efforts to increase their social status, which includes monetary support for educational opportunities and for material goods [12]. In Mozambique, as in much of the rest of Africa, women are far less financially secure than men, earning $18 \%$ of the typical salary of a man [19]. Financial dependence on men is exacerbated by low rates of secondary school completion among females, low incomes for women in rural areas, and limited employment choices for uneducated individuals other than subsistence agriculture and trading [19]. A number of studies have shown that educating 
women both reduces risky sexual behaviors and increases their economic and social options [3,27].

\section{Vertical Transmission}

Vertical transmission is mitigated by proper access to antenatal care that includes HIV testing and access to ART [28]. Without vertical transmission prevention programs, $25-48 \%$ of women will pass the virus on to their children during pregnancy, childbirth, or breastfeeding $[29,30]$. Nationwide vertical transmission prevention program coverage is inadequate, with easy access to nevirapine and zidovudine limited primarily to urban and district hospitals. The Drugs, Resources Enhancement against AIDS and Malnutrition (DREAM) project supported vertical transmission prevention implementation resulting in only a $4 \%$ transmission rate [31].

Breastfeeding is a major cause of vertical transmission in Mozambique, where replacement feeding is unaffordable for the vast majority of women. Even when provided free of charge, sociocultural norms support continued breastfeeding; mixed feeding will result in more infections than exclusive breastfeeding alone [32]. Women rarely practice early weaning that would carry the stigma of being identified as sick or for fear of the nutritional status of the infant [33]. The latter concern has been validated in the Zambian Exclusive Breastfeeding Study in which infants were less likely to be HIV-infected on rapid weaning at age 4 months, but were more likely than breastfed babies to die from other causes [32]. In Mozambique, Malawi, and Tanzania, women who breastfed but were kept on ART had a reduced chance of passing the virus on to their children than those given formula; it was noted that mixed-feeding was common in the cohort given formula [33]. In early 2010, Mozambican health authorities are currently considering policy changes based on multinational studies supporting ART for breastfeeding HIV-infected mothers to reduce breast milk-acquired infection $[34,35]$.

\section{Prevention Campaigns}

Interventions aimed at modifying personal behaviors include campaigns to reduce sex among teens (abstinence), to reduce the number of sexual partners, and to encourage monogamy within marriage (be faithful), and promote correct and consistent condom use (the $\mathrm{ABC}$ campaign) $[3,9,30,36,37]$. Obstacles to condom use are many. A prevalent belief supported by the popular media is that condoms are not necessary in relationships built on mutual respect, love and trust [36]. Due to these messages, condoms may be more often used when having a sex with non-regular partners [9,30,36,37]. Health seeking behavior is also reportedly an issue, as many Mozambicans believe certain illnesses are caused by witchcraft or curses [38]. These beliefs prompt persons who are ill to seek care from traditional healers instead of seeking testing and treatment from a local health facility.

Interventions aimed at changing culturally accepted traditions often present the greatest challenge because, unlike many structural interventions, they are not easily modified by increased funding. Stigma, discrimination, and traditional gender roles present challenges when preventing and treating HIV. HIV-infected Mozambicans are typically afraid to be open about their HIV status for fear of community stigmatization and family abandonment [39]. Women have fewer opportunities to improve their financial position as they are less well educated and do not have the option of taking mining, construction or other 'hard-labor' jobs $[39,40]$. Where women and men are valued for the number of children they produce, condom use is eschewed even if a partner fears contracting the virus [41].

Structural interventions, based on international guidelines, have been implemented to reduce risk of transmission by eliminating the re-use of needles for immunizations and medication administration and from testing blood products used in transfusions [42,43]. One structural intervention to decrease HIV transmission is the provision of universal opt-out testing in health facilities which allows for earlier diagnosis and positive prevention counseling [44]. Opt-out testing was adopted as protocol by the Mozambican Ministry of Health for pregnant women in 2006 [45]. Potential human rights issues and stigmatization of women that may result from the introduction of this strategy are detailed in the Discussion section.

Educational and health systems, particularly in rural areas, were devastated by the long periods of war; reconstruction has been slow since peace in 1992 due to inadequate funds in the face of devastation of both schools and hospitals [46]. In addition to the improvement of education and health facilities, the creation and enforcement of laws protecting women's rights are needed. One example is Mozambique's law to protect women from losing homes and property after the deaths of their husbands; despite enaction it has been enforced infrequently [47]. Property, including clothing, land, and homes will often be seized by the family of the deceased, ostensibly to ensure that it remains in the biological family of the deceased man.

\section{Adherence to ART}

A recent qualitative study of barriers to ART in Beira, Mozambique found that patient information and attitudes towards treatment, family support, and clinical confidentiality were all important barriers to health seeking behavior among those infected with HIV [48]. Assuming service availability, there are still issues regarding clinician-patient exchange (including confidentiality, 
respect and education), as well as community interventions to encourage support for HIV positive individuals within their families and communities. Poor adherence presents viral resistance, treatment failure, and higher viral loads, leading to increased viral transmission [49]. Thus, adherence is essential to any treatment program.

Two long-term studies of patient adherence have been undertaken in urban communities in Mozambique. A study of 154 people treated by the privately-funded DREAM program suggested that $82.5 \%$ of people were $>$ $90 \%$ adherent to their treatment, as estimated by the proportion that kept their ART-related appointments and maintaining lowered viral loads. Surveyed patients indicated that the visits and medicines, both free of charge nationwide, and nutritional supplements, available free in the DREAM program, but not nationwide in HIV care venues, were the most important factors in adherence. A second study, also at a DREAM clinic, suggested that $72.1 \%$ of patients had a $>95 \%$ adherence. Only $5 \%$ were believed to be adherent $<85 \%$ of the time [33]. Although these numbers from a well-funded model program are encouraging, they are not representative of national ART services that include rural areas hampered by limited budgets, transportation, extreme poverty, public financing, limited health workforce, and poor population educational levels. Systematic reviews of ART programs throughout Mozambique are needed within their broader health care context.

\section{Drug and Alcohol Use}

Little is known about drug and alcohol use in Mozambique. Most Mozambican communities are neither prosperous enough to sustain drug purchases nor located in any illicit drug distribution corridor. However, Maputo, Beira, and other smaller cities are potential ports where drugs could be imported to South Africa or Zimbabwe. Elsewhere in sub-Saharan Africa drug use of heroin, Mandrax, methamphetamine and cocaine has been rising $[50,51]$. The implications of increased HIV transmission through infected needles and increased risky behavior with the expansion of illicit drug use has been noted in South Africa, Kenya, Tanzania, Mauritius, and Nigeria $[52,53]$. At present, it is unknown whether drug use contributes to HIV infection in Mozambique's cities such as Maputo or Beira; we believe it is an important area for future research.

Alcohol use has been associated with HIV infection risk in both sub-Saharan Africa and other countries due to disinhibition and increased sexual risk-taking [54-59]. There is no published evidence of a relationship between alcohol use and HIV transmission in Mozambique. Homemade alcoholic beverages from cashew fruit, corn, and sugarcane are the cheapest type of alcohol available in rural areas and beer is widely available. We believe that it is highly plausible that there are links, and as with drug use, alcohol consumption is an important future HIV research priority.

\section{Men Who Have Sex with Men (MSM)}

MSM, male homosexuality, and bisexuality are taboo topics and practices in southern Africa. Nonetheless, key informant interviews with men living in Mombasa and Nairobi, Kenya identified an underground community of MSM [60]. It is likely that MSM exist also in southern African cities, but because of the stigma associated with homosexuality, locating people willing to discuss their homosexual sexual behavior is challenging. Imprisonments in 2009 of MSM in Uganda and Malawi merely because the men were public as to their sexual orientation underscore MSM stigma, discrimination, and human rights issues[61]. While not illegal in Mozambique, the topic is taboo and homosexuality is often not accepted. We suggest that this topic represents yet another research vacuum for Mozambique.

\section{Cultural Practices}

Some local cultural practices may place individuals at an increased risk for contracting HIV, but care must be taken to not overstress 'exotic' or 'unacceptable' behavior as seen by foreign researchers [62]. Rates of adult HIV infection are highest in the southern and central parts of the country ( $21 \%$ and $18 \%$, respectively) compared to $9 \%$ in the Northern provinces [1]. It is plausible that some socio-cultural differences may be influencing HIV prevalence rates. These include marriage practices, sexual initiation that may occur during rites of passage, sexual practices linked to 'widow cleansing,' cutting the skin during traditional medical treatment, and desires by men to have 'dry sex' $[10,12]$. Although no systematic studies link these practices to HIV infection in Mozambique, the use of non-sterile knives and blades, unprotected sex, excoriation and other sexual trauma are obvious potential risk factors for transmission [63].

Anthropological studies undertaken in Mozambique to identify patterns in marriage structures (monogamy, polygamy), type of descent pattern (matrilineal, patrilineal), and age at marriage found significant variations in behavioral and social norms within the country's 16 major ethnic groups [64]. Outside of Mozambique, ethnic groups with patrilineal descent systems typically result in a younger age at first marriage for women and a larger age gap between a husband and a younger wife [65]. Unexpectedly, the opposite may be true in Mozambique. Matrilineal societies averaged earlier-than-expected ages for marriage (15-17 years of age) and patrilineal societies had a slightly higher average age at marriage (18-21 years) [66]. Education has likely become a mitigating factor, as matrilineal systems in the rural northern regions had 
high female illiteracy rates $(85 \%-88 \%)$. The southern provinces, where patrilineal descent is common, had lower rates of illiteracy $(48 \%-77 \%)$ and had greater access to radio, television, newspapers and health information [66]. No information for men was obtained in these studies such that we do not know about discrepancies in age at marriage between men and women.

Polygamy and systems of patrilineal descent are commonly practiced throughout the country [66]. The majority of people in the southern and central parts of the country are Christian. Conversely, the north is populated by a large percentage of Muslims [63]. In Muslim Africa, rates of HIV infection are typically lower than in other regions, probably due to the closed nature of polygamous sexual networks, lower incidence of premarital sex, and much higher rates of male circumcision [67].

'Widow cleansing' (a brother having perceived sexual access to his deceased brother's widow) is practiced in some Mozambican ethnic groups [68]. A widow is encouraged to have sexual relations with a brother of the deceased husband in an effort to "cleanse" her and "rid her of bad spirits." [68] She may also marry him in a polygamous or monogamous relationship. This ceremony marks the end of a woman's grieving period. A possible HIV-related cause of the death for the husband, HIVinfection in the brother, or HIV-infection in the widow may lead to HIV transmission.

Traditional medical beliefs and traditional healers may also play a role in spreading HIV infection and hindering HIV-related treatment. Traditional healers may exacerbate spread of the disease by prescribing sex with virgins to cure HIV, performing medical treatments with unsterilized blades, or having sex with their clients for alleged therapeutic benefit [69-81]. Perhaps more commonly, traditional healers may delay and discourage people from accessing HIV care and treatment in state-run medical clinics in order to continue treatment of infected individuals through traditional means [81]. Not all healers have negative relationships with the health care system, but there is currently no formal relationship between healers and the Ministry of Health to improve health care outcomes has yet been established.

Dry sex has been reported from many parts of southern Africa and can increase the chance of HIV transmission through abrasions of the vagina, vulva, cervix, or penis [5]. Women place drying agents like herbs, disinfectants, or soaps inside the vagina to ensure dryness during intercourse [5]. The origin of this practice may be associated with the belief that vaginal dryness during intercourse allows a man to maintain his erection for a protracted time [12].

\section{Discussion}

\section{Prevention Challenges}

There are many difficulties in integrating HIV prevention messages into the Mozambican context of stigma, low autonomy for women, influence of traditional healers, and a high cultural value of pregnancy. Even when HIV/ AIDS knowledge is high, we think that culturally sanctioned methods for prevention, culturally adapted messages for HIV prevention and ART advocacy, and finding a creative way to integrate traditional healers into the health care system will be needed for long-term success in HIV programs. Lusophone Mozambique is distinctive compared to its six Anglophone neighbors. Both its Portuguese colonial and language heritage, and its troubled legacy of war and authoritarian government suggest that many prevention programs developed elsewhere will need adaptation for Mozambican conditions. Behavioral and structural interventions are not yet incorporated widely into national efforts. Among the needs are including more peer educators to dispense HIV testing and prevention information, increased access to ART, access to free condoms at truck stops, schools, clinics, and hotels, the creation and enforcement of laws protecting the legal rights of women, improved educational opportunities, and expanded male circumcision programs [82].

For the hundreds of thousands of serodiscordant couples in Mozambique and elsewhere, there is no effective method for them to protect themselves if they are not using condoms. Both men and women typically wish to have children due to a desire for a family, to meet social norms, and to indicate a successful marriage. These traditions surely challenge condom promotion within a relationship. Misconceptions about condoms may lead to paranoia or demagoguery, such as when a national church leader claimed AIDS to be a Western genocidal invention and that powder or lubrication in condoms caused HIV/AIDS [83]. So far, condoms use has be taken up by only a fraction of the population; other barrier methods like microbicides or ART used as pre-exposure prophylaxis (PrEP) that allow for pregnancy and a 'more authentic' feel during sex may have promise in the Mozambican setting. Of course, ART may reduce risk of transmission and is itself a potential prevention tool [84].

The adoption of opt-out testing only for pregnant women is complicated from a human rights perspective when community stigma is very high. Programs that overwhelmingly offer opt-out tested to pregnant women will naturally first find women to be positive, increasing serious social and marital pressures [85]. Ideally, a national strategy of opt-out testing in a high prevalence environment should be applied equally to both men and 
women whenever they visit a health provider regardless of chief complaint.

Despite an influx of funds from the President's Emergency Plan for AIDS Relief (PEPFAR) and the Global Fund to Fight AIDS, Tuberculosis, and Malaria (Global Fund), Mozambique remains woefully undercapacitated in its medical infrastructure, social acceptance of risk reduction strategies, and its health manpower [86]. Increased funding has improved HIV clinical services in much of urban Mozambique, but clinics in rural areas continue to have poor physical infrastructures and suffer from drug supply chain management issues. This creates a challenge for nurses, medical technicians, and doctors seeking to ensure universal access to counseling, testing, clinical care, stable ART access, ABC prevention services, and PMTCT. The dearth of health care providers is a deficit throughout sub-Saharan Africa. It is estimated that an additional 2.4 million health physicians, nurses, and midwives are necessary to meet universal health intervention coverage targets in the 57 most resource-constrained countries, notably Mozambique [87]. This discrepancy demands an urgent and realistic plan to increase production and retention of health care providers, particularly outside the capital city of Maputo where over half of small number of Mozambican doctors practice, and to extend the reach and increase the quality of health services $[88,89]$.

Those professionals who are available often prefer to live and work in Maputo, as the school system quality and career opportunities for their families are greater. Incentives for doctors and nurses to live in rural areas have been implemented, but the number choosing to remain in remote areas is still small. Additional incentives must be provided, including quality education in rural areas for children, good housing for health care workers, and a more rewarding work environment. Task shifting of work from doctors to nurses, medical technicians, and community workers is also essential, as is a stemming of the tide of recruiting nurses and doctors from Africa to higher income Organization for Economic Co-operation and Development (OECD) countries [90-93].

\section{Treatment Challenges}

Getting people to access ART is not straightforward, even when it is freely available. With high levels of stigma associated with HIV, openly taking life-long medication can present undesirable or even untenable social challenges, given the rarity with which chronic diseases are managed with continuous medication therapy, particularly in rural areas. The scaling up of HIV treatment in Mozambique has progressed at a slower rate than in neighboring Zambia, whose health challenges are similar to those in Mozambique [94,95]. Zambia is a more urbanized nation and never suffered from a colonial war of independence nor a civil war. Training, recruiting and retaining health care workers in remote/rural areas are part of Mozambique's chronic challenge. In 2004, Mozambique was believed to have 514 doctors, 3,954 nurses, and 2,229 midwives for a population at that time of $\approx 19$ million [96]. By 2006, Mozambican health officials estimated that there were only 1.26 health care workers (of any profession) per 1,000 people [97]. The government has proposed a US $\$ 2$ billion investment in long and short-term education programs to increase the number of doctors, medical technicians, nurses and others. Even with this investment, Mozambique will only have a projected 1.87 health care workers per 1,000 people by 2015 [98].

Barriers to prevention and treatment access are often limited by finances. Primarily donor funded, Mozambique's HIV treatment programs still face an uphill battle. A senior National Institutes of Health physician seconded to a high-level White House policy advisory position has stated that "...doubling or tripling PEPFAR's funding is not the best use of international health funding. In focusing so heavily on HIV/AIDS treatments, the United States misses huge opportunities" [99]. True to this no-moremoney-for-ART philosophy, no substantial increase from base funding for HIV treatment from either the PEPFAR or the Global Fund has accompanied the WHO change in recommended treatment guidelines changing the routine start of ART from 250 to $350 \mathrm{CD} 4+$ cells/ $\mu \mathrm{L}$ [100]. Forty percent more persons should be on ART, but few in Mozambique will receive it. This challenge, in part due to the current financial crisis and donor fatigue, will limit the support provided for those HIV positive and for prevention interventions within the country.

\section{Conclusions}

Mozambique has one of the highest HIV prevalence and incidence rates, showing few signs of abatement. Infrastructures are poor, due in part to colonial mismanagement of the country and due to the destruction of the few services that existed during the war of independence against the Portuguese and/or the civil war. Cultural norms around acceptability of multiple sexual partners and the low socio-economic status of women have not changed notably. Health care for people living with HIV/ AIDS has become available nationwide, including for the rural population, but clinics offering services are often located far from villages and suffer from supply chain management issues. Stigma, social norms, and education must be addressed by directed interventions (increased educational opportunities, behavioral change campaigns, educational campaigns) aimed at overcoming and minimizing obstacles to health care in Mozambique. Building the health system infrastructure of Mozambique, including manpopwer, is essential for long term progress. 


\section{Competing interests}

The authors declare that they have no competing interests.

\section{Authors' contributions}

All of the authors contributed to researching, constructing, and editing the final manuscript.

\section{Acknowledgements}

The authors would like to thank Meredith Bortz for her assistance

\section{Author Details}

'Vanderbilt Institute for Global Health, Vanderbilt University School of Medicine, Nashville, TN, 37203 USA, 2Department of Preventive Medicine, Vanderbilt University School of Medicine, Nashville, TN, 37232 USA ${ }^{3}$ Department of Pediatrics, Vanderbilt University School of Medicine, Nashville, TN, 37232 USA, 4Friends in Global Health, Maputo and Quelimane, Mozambique and ${ }^{5}$ Department of Community Health, Faculty of Medicine, Universidade Eduardo Mondlane, Maputo, Mozambique

Received: 17 December 2009 Accepted: 8 June 2010 Published: 8 June 2010

\section{References}

1. Multi-Sectoral Technical Group for the Fight Against HIV/AIDS in Mozambique: Report on the Revision of the Data from HIV Epidemiological Surveillance: Round 2007. 2008 [http:// www.misau.gov.mz/pt/content/download/4637/28101/../ Ronda2007EN.pdf. Mozambique Ministry of Health Accessed on August 232009

2. Finnegan W: A complicated war: the harrowing of Mozambique. Berkeley: University of California Press; 1992.

3. Machel JZ: Unsafe sexual behaviour among schoolgirls in Mozambique: a matter of gender and class. Reprod Health Matters 2001, 9(17):82-90.

4. Joint United Nations Programme on HIV/AIDS (UNAIDS): Report on the global HIV/AIDS epidemic 2008. UNAIDS/08.25E/JC1510E 2008 [http:// www.unaids.org/en/KnowledgeCentre/HIVData/GlobalReport/2008/ 2008 Global report.asp]. Accessed on November 14, 2009

5. Myer L, Kuhn L, Stein ZA, Wright TC Jr, Denny L: Intravaginal practices, bacterial vaginosis, and women's susceptibility to HIV infection: epidemiological evidence and biological mechanisms. Lancet Infect Dis 2005, 5(12):786-794

6. Prata N, Morris L, Mazive E, Vahidnia F, Stehr M: Relationship between HIV risk perception and condom use: Evidence from a population-based survey in Mozambique. Int Fam Plan Perspect 2006, 32(4):192-200.

7. The POLICY Project for Bureau for Africa: HIV/AIDS in Southern Africa: Background, Projections, Impacts, and Interventions. 2001 [http:// www.policyproject.com/pubs/countryreports/SoAf10-01.pdf]. Accessed on October 24, 2009

8. Hawkins K, Price N, Mussa F: Milking the cow: young women's construction of identity and risk in age-disparate transactional sexual relationships in Maputo, Mozambique. Glob Public Health 2009, 4(2):169-182.

9. Karlyn AS: Intimacy revealed: sexual experimentation and the construction of risk among young people in Mozambique. Cult Health Sex 2005, 7(3):279-292.

10. Askin KD, Koenig DM: Women and international human rights law. Ardsley, N.Y.: Transnational Publishers; 1999.

11. Bagnol B, Chamo E: Intergenerational relationship in Mozambique: what is driving young women and older men? Sexual Health Exchange 2004, 3:10-11

12. Bagnol B, Mariano E: Vaginal practices: eroticism and implications for women's health and condom use in Mozambique. Cult Health Sex 2008 , 10(6):573-585.

13. IRIN PlusNews: Global HIV/AIDS news and analysis: Mozambique: Widows risk HIV in purification rites. 2008 [http://www.plusnews.org/ Report.aspx?Reportld=81496]. Accessed on October 232009

14. Modjarrad K, Chamot E, Vermund SH: Impact of small reductions in plasma HIV RNA levels on the risk of heterosexual transmission and disease progression. AIDS 2008, 22(16):2179-2185.

15. Modjarrad K, Vermund S: Impact of treating coinfections on HIV-1 viral load: a systematic review and meta-analysis. Lancet ID 2009 in press.
16. Halperin DT, Epstein H: Concurrent sexual partnerships help to explain Africa's high HIV prevalence: implications for prevention. Lancet 2004, 364(9428):4-6.

17. Integration of Sexually Transmitted Infection (STI) Prevention, Diagnosis, and Treatment into HIV Clinical Care in Mozambique. In Unpublished technical report Mozambique Ministry of Health; 2008.

18. Westoff CF: Recent trends in rates of sexual activity in sub-Saharan Africa. J Biosoc Sci 2007, 39(6):895-904

19. Instituto Nacional de Estatística and Ministério da Saúde, ORC Macro/ Demographic and Health Services Program: Moçambique Inquérito Demográfico e de Saúde 2003. 2005 [http://www.measuredhs.com/ pubs/pdf/FR161/FR161.pdf]. Accessed on July 14, 2009

20. Agha $S$, Hutchinson $P$, Kusanthan $T$ : The effects of religious affiliation on sexual initiation and condom use in Zambia. J Adolesc Health 2006, 38(5):550-555.

21. Kaestle CE, Halpern CT, Miller WC, Ford CA: Young age at first sexual intercourse and sexually transmitted infections in adolescents and young adults. Am J Epidemiol 2005, 161(8):774-780.

22. Levinson D: Ethnic groups worldwide: a ready reference handbook. Phoenix, Ariz: Oryx Press; 1998

23. Kok P, Gelderblom D, Oucho J, Van Zyl JA: Migration in South and Southern Africa: Dynamics and determinants. Human Science Research Council Press 2005:179-183.

24. Kalipeni E: HIV and AIDS in Africa: beyond epidemiology. Malden, MA: Blackwell Publishers; 2004

25. Odaga A, Heneveld W: Girls and schools in Sub-Saharan Africa: from analysis to action. World Bank technical paper 1995, 54(298):112.

26. Agha S, Karlyn A, Meekers D: The promotion of condom use in nonregular sexual partnerships in urban Mozambique. Health Policy Plan 2001, 16(2):144-151

27. Shisana $O$, Davids $A$ : Correcting gender inequalities is central to controlling HIV/AIDS. Bull World Health Organ 2004, 82(11):812.

28. Stringer EM, Sinkala M, Stringer JS, Mzyece E, Makuka I, Goldenberg RL, Kwape P, Chilufya M, Vermund SH: Prevention of mother-to-child transmission of HIV in Africa: successes and challenges in scaling-up a nevirapine-based program in Lusaka, Zambia. AIDS 2003, 17(9):1377-1382.

29. Montano M, Russell M, Gillbert P, Thior I, Lockman S, Shapiro R, Chang SY, Lee TH, Essex M: Comparative prediction of perinatal human immunodeficiency virus type 1 transmission, using multiple virus load markers. J Infect Dis 2003, 188(3):406-413.

30. Wiktor SZ, Ekpini E, Nduati RW: Prevention of mother-to-child transmission of HIV-1 in Africa. AIDS 1997, 11(Suppl B):S79-87

31. Marazzi MC, Bartolo M, Emberti Gialloreti L, Germano P, Guidotti G, Liotta G, Magnano San Lio M, Mancinelli S, Modolo MA, Narciso P, et al.: Improving adherence to highly active anti-retroviral therapy in Africa: the DREAM programme in Mozambique. Health Educ Res 2006, 21(1):34-42.

32. Kuhn L, Aldrovandi GM, Sinkala M, Kankasa C, Semrau K, Mwiya M, Kasonde P, Scott N, Vwalika C, Walter J, et al.: Effects of early, abrupt weaning on HIV-free survival of children in Zambia. NEngl J Med 2008 359(2):130-141

33. Palombi L, Marazzi MC, Voetberg A, Magid NA: Treatment acceleration program and the experience of the DREAM program in prevention of mother-to-child transmission of HIV. AIDS 2007, 21(Suppl 4):S65-71.

34. Kumwenda NI, Hoover DR, Mofenson LM, Thigpen MC, Kafulafula G, Li Q, Mipando L, Nkanaunena K, Mebrahtu T, Bulterys M, et al: Extended antiretroviral prophylaxis to reduce breast-milk HIV-1 transmission. $N$ Eng/ J Med 2008, 359(2):119-129.

35. Pini P, Kleinert S: SWEN--when authors disagree. Lancet 2008, 372(9635):269-270.

36. Manuel S: Obstacles to condom use among secondary school students in Maputo city, Mozambique. Cult Health Sex 2005, 7(3):293-302.

37. Mola OD, Mercer MA, Asghar RJ, Gimbel-Sherr KH, Gimbel-Sherr S, Micek MA, Gloyd SS: Condom use after voluntary counselling and testing in central Mozambique. Trop Med Int Health 2006, 11(2):176-181.

38. Van Dyk A: Traditional African beliefs and customs: Implications for AIDS education and prevention in Africa. South African Journal of Psychology 2001, 31:60-66.

39. PlusNews: Mozambique: HIV-infected women blamed and shunned. 2007 [http://www.plusnews.org/Report.aspx?Reportld=71727]. Accessed on April 29, 2009 
40. Woods V, Monteiro N: Gender, Reproductive Rights and the Politics of HIV/AIDS in Mozambique. ISA's 49th Annual Convention, San Francisco, California 2008.

41. Passador LH: "Tradition," person, gender, and STD/HIV/AIDS in southern Mozambique. Cad Saúde Publica 2009, 25(3):687-693.

42. Cunha L, Plouzeau C, Ingrand P, Gudo JP, Ingrand I, Mondlane J, Beauchant M, Agius G: Use of replacement blood donors to study the epidemiology of major blood-borne viruses in the general population of Maputo, Mozambique. J Med Virol 2007, 79(12):1832-1840.

43. World Health Organization (WHO): Safety of injections WHO-UNICEFUNFPA joint statement on the use of auto-disable syringes in immunization services. Vaccines and Biologicals 2009 [http:// www.who.int/vaccines-documents/DocsPDF99/www9948.pdf] Accessed on August 20, 2009

44. Vermund SH, Wilson CM: Barriers to HIV testing--where next? Lancet 2002, 360(9341):1186-1187.

45. MISAU/UNICEF/WHO: Mozambique Progress Report: High Level Global Partners Forum Prevention of Mother to Child Transmission, South Africa, 26-27 November 2007. [http://www.who.int/countries/moz/ publications/moz progress.pdf].

46. Weinstein M: Mozambique: A Fading U.N. Success Story. Journal of Democracy 2002, 13(1):141-156.

47. Tanner C: Law-Making in an African Context: The 1997 Mozambican Land Law. FAO Legal Paper Online 2002 [http://www.sarpn.org.za/ CountryPovertyPapers/Mozambique/Legal/tanner.php]. Accessed on March 15, 2009

48. Posse M, Baltussen R: Barriers to Access to Antiretroviral Treatment in Mozambique, as Perceived by Patients and Health Workers in Urban and Rural Settings. AIDS Patient Care and STDs 2009, 23(10):867-875.

49. Ledergerber B, Egger M, Erard V, Weber R, Hirschel B, Furrer H, Battegay M, Vernazza P, Bernasconi E, Opravil M, Kaufmann D, Sudre P, Francioli P, Telenti A: AIDS-related opportunistic illnesses occurring after initiation of potent antiretroviral therapy: the Swiss HIV Cohort Study. JAMA 1999, 282(23):2220-6.

50. Anderson P: Global use of alcohol, drugs and tobacco. Drug Alcohol Rev 2006, 25(6):489-502

51. Csete J, Gathumbi A, Wolfe D, Cohen J: Lives to save: PEPFAR, HIV, and injecting drug use in Africa. Lancet 2009, 373(9680):2006-2007.

52. Croce F, Fedeli P, Dahoma M, Deho L, Ramsan M, Adorni F, Corvasce S, Galli M: Risk factors for HIV/AIDS in a low HIV prevalence site of subSaharan Africa. Trop Med Int Health 2007, 12(9):1011-1017.

53. Needle R, Kroeger K, Belani H, Hegle J: Substance abuse and HIV in subSaharan Africa: Introduction to the Special Issue. African Journal of Drug and Alcohol Studies 2006, 5(2):83-94.

54. Willis J: Drinking crisis? change and continuity in cultures of drinking in sub-saharan Africa. African Journal of Drug and Alcohol Studies 2006, 5(1):2-15

55. Odejide O: Alcohol Policies in Africa. African Journal of Drug and Alcohol Studies 2006, 5(1):27-39.

56. Fisher JC, Bang H, Kapiga SH: The association between HIV infection and alcohol use: a systematic review and meta-analysis of African studies. Sex Transm Dis 2007, 34(11):856-863.

57. Mager A: "White liquor hits black livers": meanings of excessive liquor consumption in South Africa in the second half of the twentieth century. Soc Sci Med 2004, 59(4):735-751.

58. Pretorius L, Naidoo A, Reddy SP: "Kitchen cupboard drinking": a review of South African women's secretive alcohol addiction, treatment history, and barriers to accessing treatment. Soc Work Public Health 2009, 24(1-2):89-99.

59. Abdool Karim Q: Barriers to preventing human immunodeficiency virus in women: experiences from KwaZulu-Natal, South Africa. J Am Med Womens Assoc 2001, 56(4):193-196.

60. Van Griensven F: Men who have sex with men and their HIV epidemics in Africa. AIDS 2007, 21:1361-1362.

61. Gettleman J: Americans' Roles Seen in Uganda Anti-Gay Push. New York Times 2010 [http://www.nytimes.com/2010/01/04/world/africa/ 04uganda.html]. Accessed on April 5

62. Gausset Q: AIDS and cultural practices in Africa: the case of the Tonga (Zambia). Soc Sci Med 2001, 52(4):509-518

63. Gengenbach H: Boundaries of Beauty: Tattooed Secrets of Women's History in Magude District, Southern Mozambique. Journal of Women's History 2003, 14(4):106-141.
64. Ndege GO: Culture and customs of Mozambique. Westport, Conn.: Greenwood Press; 2007.

65. Lesthaeghe R: Family formation and dissolution: the two transitions. Tijdschr Sociol 1987, 8(2-3):9-33. 279

66. Arnaldo C: Ethnicity and Marriage Patterns in Mozambique. African Population Studies 2004, 19(1):143-164.

67. Gray PB: HIV and Islam: is HIV prevalence lower among Muslims? Soc Sci Med 2004, 58(9):1751-1756.

68. Babb D, Pemba P, Seatlanyane P, Charalambous S, Curchyard G, Grant A Use of traditional medicine in the era of antiretroviral therapy: experience from South Africa. eJournal of the International AIDS Society 2004:B10640.

69. Bodeker G, Kabatesi D, King R, Homsy J: A regional task force on traditional medicine and AIDS. Lancet 2000, 355(9211):1284.

70. Fleming J: Mozambican healers join government in fight against AIDS. J Int Assoc Physicians AIDS Care 1995, 1(2):32.

71. Green EC, Zokwe B, Dupree JD: The experience of an AIDS prevention program focused on South African traditional healers. Soc Sci Med 1995, 40(4):503-515.

72. Homsy J, King R, Balaba D, Kabatesi D: Traditional health practitioners are key to scaling up comprehensive care for HIV/AIDS in sub-Saharan Africa. AIDS 2004, 18(12):1723-1725.

73. King R: Collaboration with traditional healers in HIV/AIDS prevention and care in sub-Saharan Africa: A literature review. Joint United Nations Programme on HIV/AIDS. Volume UNAIDS Best Practice Collection. Geneva, Switzerland 2000 [http://data.unaids.org/Publications/IRC-pub01/JC299TradHeal en.pdf]

74. Lane T: In South Africa, Wives' HIV Prevention Beliefs Affect Condom Use with Spouse. International Family Planning Perspectives 2004, 30(3):150-151

75. Liverpool J, Alexander R, Johnson M, Ebba EK, Francis S, Liverpool C: Western medicine and traditional healers: partners in the fight against HIV/AIDS. J Nat/ Med Assoc 2004, 96(6):822-825.

76. Mills E, Singh S, Wilson K, Peters E, Onia R, Kanfer I: The challenges of involving traditional healers in HIV/AIDS care. Int J STD AIDS 2006 17(6):360-363.

77. Morris K: South Africa tests traditional medicines. Lancet Infect Dis 2002, 2(6):319.

78. Munk K: Traditional healers, traditional hospitals and HIV/AIDS: a case study in KwaZulu-Natal. AIDS Anal Afr 1997, 7(6):10-12

79. Richter M: Traditional Medicines and Traditional Healers in South Africa. Treatment Action Campaign and AIDS Law Project 2003 [http:// www.tac.org.za/Documents/ResearchPapers/ Traditional Medicine briefing.pdf]

80. Zachariah R, Nkhoma W, Harries AD, Arendt V, Chantulo A, Spielmann MP, Mbereko MP, Buhendwa L: Health seeking and sexual behaviour in patients with sexually transmitted infections: the importance of traditional healers in Thyolo, Malawi. Sex Transm Infect 2002 78(2):127-129.

81. Askin KD: Traditional healers' practices under AIDS spotlight. Mail \& Guardian Online 2006 [http://www.mg.co.za/article/2006-12-23traditional-healers-practices-under-aids-spotlight]. Accessed on July 12 2009

82. Jewkes R, Morrell R, Christofides N: Empowering teenagers to prevent pregnancy: lessons from South Africa. Cult Health Sex 2009:1

83. BBC News: Shock at archbishop condom claim. 2007 [http:// news.bbc.co.uk/2/hi/africa/7014335.stm]. Accessed on April 12, 2009

84. Vermund SH, Allen KL, ABdool Karim Q: HIV Prevention Science at a Crossroads: Advances in Reducing Sexual Risk. Curr Opin HIV AIDS 2009, 4:266-73.

85. Csete J, Schleifer R, Cohen J: "Opt-Out" testing for HIV in Africa: A Caution. The Lancet 2004, 363(9407):493-494.

86. Chao S, Kostermans K: Improving Health for the Poor in Mozambique: The Fight Continues (HPN Discussion Paper). 2002 [http:// siteresources.worldbank.org/HEALTHNUTRITIONANDPOPULATION/ Resources/281627-1095698140167/Chao-ImprovingHealth-whole.pdf The World Bank Accessed on August 20, 2009

87. World Health Organization (WHO): Spotlight on health workforce statistics. 2008 [http://www.who.int/hrh/statistics/spotlight/en/ index.html]. Accessed on May 2, 2009

88. Dovlo D: Using mid-level cadres as substitutes for internationally mobile health professionals in Africa. A desk review. Hum Resour Health 2004, 2(1):7 
89. Pearson CR, Micek M, Simoni JM, Matediana E, Martin DP, Gloyd S: Modified directly observed therapy to facilitate highly active antiretroviral therapy adherence in Beira, Mozambique. Development and implementation. J Acquir Immune Defic Syndr 2006, 43(Suppl 1):S134-141.

90. Gimbel-Sherr SO, Micek MA, Gimbel-Sherr KH, Koepsell T, Hughes JP, Thomas KK, Pfeiffer J, Gloyd SS: Using nurses to identify HAART eligible patients in the Republic of Mozambique: results of a time series analysis. Hum Resour Health 2007, 5:7.

91. Bevan S: Britain accused of ignoring nurse-recruitment ban. The Lancet 2005, 366(9501):1915-1916.

92. Brush BL, Sochalski J, Berger AM: Imported Care: Recruiting Foreign Nurses To U.S. Health Care Facilities. Health Affairs 2004, 23(3):78-87.

93. Buchan J: International Recruitment of Nurses: Policy and Practice in the United Kingdom. Health Services Research 2007, 42(3 pt 2):1321-1335.

94. Bolton-Moore C, Mubiana-Mbewe M, Cantrell RA, Chintu N, Stringer EM, Chi BH, Sinkala M, Kankasa C, Wilson CM, Wilfert CM, et al: Clinical outcomes and $\mathrm{CD} 4$ cell response in children receiving antiretroviral therapy at primary health care facilities in Zambia. JAMA 2007, 298(16):1888-1899.

95. Stringer JS, Zulu I, Levy J, Stringer EM, Mwango A, Chi BH, Mtonga V, Reid S, Cantrell RA, Bulterys M, et al.: Rapid scale-up of antiretroviral therapy at primary care sites in Zambia: feasibility and early outcomes. JAMA 2006, 296(7):782-793.

96. Joint United Nations Programme on HIV/AIDS (UNAIDS): AIDS Epidemic Update: Special Report on HIV/AIDS: December 2006. UNAIDS/06.29E 2006 [http://data.unaids.org/pub/EpiReport/2006/ 2006 EpiUpdate en.pdf]. Accessed on July 22, 2009

97. Hirschhorn LR, Oguda L, Fullem A, Dreesch N, Wilson P: Estimating health workforce needs for antiretroviral therapy in resource-limited settings. Hum Resour Health 2006, 4:1

98. Ministério da de, Direcção Nacional de Planificação e Cooperação, Departamento de Informação para a Saúde, Mozambique: Plano Estratégico do Sistema de Informaçães para a Saúde - 2009-2014. 2009 [http://www.who.int/healthmetrics/library/countries/ HMN MOZ StrPlan Draft 200906 pt.pdf]. Accessed on November 14, 2009

99. Denny CC, Emanuel EJ: US Health AIDS Beyond PEPFAR. The Mother \& Child Campaign. JAMA 2008, 300:2048-5.

100. WHO: Rapid Advice: Antiretroviral Therapy for HIV Infection in Adults and Adolescents. Geneva: WHO; 2009:10-14.

\section{Pre-publication history}

The pre-publication history for this paper can be accessed here: http://www.biomedcentral.com/1472-698X/10/15/prepub

doi: 10.1186/1472-698X-10-15

Cite this article as: Audet et al., Sociocultural and epidemiological aspects of HIV/AIDS in Mozambique BMC International Health and Human Rights 2010, 10:15

\section{Submit your next manuscript to BioMed Central} and take full advantage of:

- Convenient online submission

- Thorough peer review

- No space constraints or color figure charges

- Immediate publication on acceptance

- Inclusion in PubMed, CAS, Scopus and Google Scholar

- Research which is freely available for redistribution

Submit your manuscript at www.biomedcentral.com/submit
C Biomed Central 